\title{
DESAFIOS DEMOCRÁTICOS À CONSTRUÇÃO E IMPLEMENTAÇÃO DE INDICADORES: O CASO DO “PROGRAMA CIDADES SUSTENTÁVEIS”
}

\author{
Danilo Melo* \\ Hans Michael Van Bellen**
}

\begin{abstract}
Resumo
O conceito de Cidades Sustentáveis, que poderia ser em princípio um oximoro, tem sido amplamente utilizado no campo teórico e das práticas, inclusive pelo governo. No Brasil, a partir de 2012, a sociedade civil organizada promove o "Programa Cidades Sustentáveis (PCS)" que tem por objetivo funcionar como uma agenda para a sustentabilidade e tem como um de seus fundamentos os indicadores para monitoramento das metas de gestão pública. Este artigo procura compreender o processo de construção e implementação desses indicadores, a partir de entrevistas semiestruturadas com atores da sociedade civil organizada que apoiam municípios no desenvolvimento do plano de metas e escolha/ coleta de indicadores. Percebemos que o PCS avança ao destacar a importância de indicadores como instrumento de gestão no nível municipal e desenvolver bases de dados, no entanto, ainda encontra desafios quanto ao data-driveness, à governança dos indicadores, sobretudo em comunicar e traduzir uma noção clara de sustentabilidade.
\end{abstract}

Palavras-chave: Cidades Sustentáveis. Indicadores de sustentabilidade. Controle social. Governança ambiental. Governança sustentável.

\footnotetext{
* Doutorando em Administração pela Universidade Federal de Santa Catarina (UFSC), Docente do Departamento de Governança Pública da Universidade do Estado de Santa Catarina (UDESC).E-mail: danilo.melo@udesc.br

** Doutor em Engenharia de Produção pela Universidade Federal de Santa Catarina, Pós-Doutor junto a University of California

- Berkeleyem, Docente dos Programas de Pós-Graduação em Administração e Contabilidade da Universidade Federal de Santa Catarina (UFSC). E-mail: hansmichael.vanbellen@gmail.com
} 


\section{Contextualização}

O desenvolvimento sustentável é um conceito polissêmico, incluindo distintas dimensões, a econômica, a social e a ambiental, por exemplo, assim como prazos, curto e longo prazo (SACHS, 2007). Além disso, o enfoque pode estar no elemento humano ou no elemento não humano; portanto, a discussão também é repleta de dicotomias. A falta de um amplo consenso sobre o termo, nem por isso reduziu a popularidade do conceito (BELL; MORSE, 2008) que tem sido utilizado no âmbito acadêmico, empresarial e de governo.

O termo é carregado de valor e ao mesmo tempo em que aponta para um devir,engaja em práticas de gestão.Para Dahl(1997) “[...] existe uma forte relação entre os princípios, a ética, as crenças e os valores que fundamentam uma sociedade ou comunidade e sua concepção de sustentabilidade." Ou seja, é preciso saber para onde se pretende ir para que se possa medir a direção e o alcance dos objetivos. "O grau de sustentabilidade é relativo em função do campo ideológico ambiental ou da dimensão em que cada ator se coloca" (VAN BELLEN, 2006, p. 25); então, para operacionalizar o conceito, as medições são indispensáveis. A forma de medir, portanto, ajuda na redefinição pela tangibilidade do conceito, ainda que incompleto, e com isso auxilia a estabelecer políticas e avaliar desempenho.

É, sobretudo, necessário repensar as estruturas e os processos de tomada de decisão que afetam o meio ambiente (LEME, 2016). No Brasil, o SISNAMA, criado em 1981, previa "um modelo de gestão com participação da sociedade civil e descentralizado entre os entes federados" (LEME, 2016, p. 148). E, nesse sentido, a estrutura básica de governança ambiental no Brasil, para Moura e Bezerra (2016), engloba: conselhos estaduais e municipais e conselhos gestores temáticos, das bacias hidrográficas e de unidades de conservação, por exemplo. Destacam-se, ainda, as Agendas 21 Locais nos municípios. Para tanto, o MMA publica e divulga cartilhas para criação e construção do projeto com o Plano Local de Desenvolvimento Sustentável (FONSECA, 2016).

O passo a passo da Agenda 21 Local é considerado um manual de "boa governança" e essas receitas são impostas por agentes financiadores de boas práticas. Os fatores de insucesso dessa agenda envolvem a adoção generalizada da metodologia padrão, que não contribui para o processo local, e não foca os resultados práticos das iniciativas. Mais que isso, implementouse a Agenda como projeto, mas pouco como processo (FONSECA, 2016). Hector Leis (1999) argumenta que a Agenda 21 representou um passo significativo para a governança de questões globais baseada em processos participativos e democráticos; no entanto, não estabeleceu compromissos entre as partes, nem políticos, nem éticos, e, por isso, pouco avançou com 
relação a Estocolmo. O autor destaca, assim, a dupla condição da crise ambiental: conjuntural e civilizatória.

Além dos espaços supracitados, é possível encontrar - tanto no campo teórico quanto no campo de práticas - o conceito de Cidades Sustentáveis. Este termo que, em princípio, poderia até ser entendido pela dimensão espacial da sustentabilidade (SACHS, 2007) como um conceito antagônico, quando se encarada a cidade como elemento concentrador de problemas ambientais, agora passa a ser discutido academicamente como construto e empiricamente como agenda da sociedade civil. Este artigo pretende discutir o Programa Cidades Sustentáveis (PCS), uma realização da sociedade civil organizada que pretende funcionar como uma agenda para a sustentabilidade e tem como um de seus fundamentos a utilização de indicadores.

Alguns trabalhos no Brasil discutem o movimento da sociedade civil na busca por cidades justas, democráticas e sustentáveis (NASCIMENTO et al., 2016). O Movimento Nossa BH, por exemplo, é analisado por Nascimento et al. (2016) a partir da participação popular e da esfera pública, apresentando os desafios do movimento em criar espaços de interlocução para controle social e democrático. Percebemos, então, a participação da sociedade civil na gestão pública local fazendo avançar o controle social, a transparência e reconstruindo a noção de cidadania deliberativa e de administração pública (LUCHMANN, 2002; SCHOMMER; NUNES; MORAES, 2011; KEINERT, 2000; ANDION, 2012). Coloca-se, ainda, o desafio de construção institucional e organizacional que coordene atores na resolução de problemas do território, para uma governança sustentável (MENEZES; RONCONI; SERVA, 2016; PECQUEUR, 2006).

Este artigo tem por objetivo, portanto, compreender o processo de construção e implementação dos indicadores do Programa Cidades Sustentáveis, ampliando a discussão para além do diálogo sobre engajamento e participação popular na esfera pública, assumindo os próprios indicadores como objeto, discutindo o processo de tradução do conceito em nível local, a governança dos indicadores, pelas escolhas e pelos desafios ao implantar a ferramenta.

\section{Indicadores de sustentabilidade}

$\mathrm{Na}$ passagem do conceito de sustentabilidade à ação, surge a necessidade de se pensar em indicadores. A utilização dos indicadores permite operacionalizar o conceito e atribui sentido ao traduzi-lo em algo mensurável. A ideia de usar indicadores torna-se popular e várias agências e governos passam a dedicar recursos para seu desenvolvimento (BELL; MORSE, 2008; VAN BELLEN, 2006). Com isso, vê-se um "[...] important 
shift away from 'sustainable' as an appealing through rhetorical adjective to sustainable' becoming both a descriptor of something and a target to achieve" (BELL; MORSE, 2008, p. 5).

Van Bellen (2006, p. 54-55) apresenta algumas utilidades das medidas:

- Auxiliam os tomadores de decisão a compreender melhor em termos operacionais, o que o conceito de desenvolvimento sustentável significa, funcionando como ferramentas de explicação pedagógicas e educacionais;

- Auxiliam na escolha de alternativas políticas, direcionando para metas relativas à sustentabilidade. As ferramentas fornecem um senso de direção para os tomadores de decisão, e quando escolhem alternativas de ação, funcionam como ferramentas de planejamento; - Avaliam o grau de sucesso no alcance das metas estabelecidas referentes ao desenvolvimento sustentável, sendo essas medidas ferramentas de avaliação.

Um dos desafios da Agenda 21, por exemplo, consiste em definir indicadores de desempenho para a sustentabilidade. Isso para que seja possível acompanhar e ultrapassar o caráter estático do documento, para pensar a sustentabilidade como processo, norteado pelos princípios acordados de forma participativa. Nesse sentido, “[...] destaca-se o papel dos indicadores de sustentabilidade, nas etapas de diagnóstico e prognóstico, como ferramenta de estabelecimento de visão de conjunto e maior integração dos componentes de sustentabilidade" (MALHEIROS; PHLIPPI JR; COUTINHO, 2008, p. 17). No Brasil, Malheiros, Phlippi Jr. e Coutinho (2008) destacam a dificuldade em amarrar políticas públicas e indicadores, o que na visão dos autores traria avanços para accountability democrática e participativa.

$\mathrm{O}$ indicador de sustentabilidade tem sido apontado, portanto, como um instrumento de gestão (e quiçá de governança) que sintetiza e aponta uma tendência ou um estado e representa um atributo de um sistema - qualidade, características, propriedade. Para a Organização para a Cooperação e Desenvolvimento Econômico (OECD) “[...] um indicador deve ser entendido como um parâmetro, ou valor derivado de parâmetros que apontam e fornecem informações sobre o estado de um fenômeno, com uma extensão significativa" (VAN BELLEN, 2006, p. 42). Nesse sentido, podem ser descritivo ou normativo e devem ser significativos para os tomadores de decisão e para o público, à medida que um de seus principais objetivos é comunicar. Além disso, dentre as principais funções dos indicadores para Tunstall (1994 apud VAN BELLEN, 2006, p. 43) estão: “[...] i) avaliação de condições e tendências; ii) comparação entre lugares e situações; iii) avaliação de condições e tendências em relação às metas e aos objetivos; iv) prover informações de advertência; v) antecipar 
futuras condições e tendências”. Ou seja, além de comunicar e informar sobre o progresso de uma determinada meta, é um recurso para apontar tendências e comparar lugares no espaço/tempo.

Mas nem sempre todos os elementos, dentro das dimensões do desenvolvimento sustentável, são facilmente mensuráveis. É comum enfrentar dificuldades na escolha e no uso de indicadores quanto: à viabilidade e disponibilidade de dados, ao desejo dos governos em se apresentar nas melhores posições ao optar pelos indicadores, ao reducionismo de dimensões complexas e à obsessão por quantificação por parte de científicas e policy-makers.

[...] we end up measuring things that can be measured and not things that should be measured, if at all possible. [...] Our key premise is that the approach to measurement is always based on an individual's vision of sustainability, which in turn can be changed depending upon the measurement mindset. (BELL; MORSE, 2008, p. xvii-xviii).

À medida que a noção e a visão de sustentabilidade orientam a construção dos indicadores, considera-se que julgamentos de valor estão sempre presentes (VAN BELLEN, 2006); por isso, é necessário discuti-los e evidenciá-los. Nesse sentido, faz-se necessário dialogar com os atores, de forma ampliada, sobre essa visão. $\mathrm{E}$ assim, podemos considerar duas categorias de orientações na tomada de decisão e escolha de indicadores: topdown e down-up. Enquanto alguns indicadores são originados por técnicos ou pelos próprios gestores públicos, outros são dialogados e definidos pelas pessoas comuns. "The Norwich SIs [...] represented what can best be termed the views of at least some laypeople" (BELL; MORSE, 2008, p. 81).

Meadows (1988) relata como problemas: i) superagregação - muitos dados condensados em um mesmo índice, escondendo aspectos relevantes e dificultando a interpretação; ii) viés de mensuração data driveness, ou seja, mensurar aquilo que é mensurável, não aquilo que é relevante. Esse aspecto de superagregação traz para a discussão a questão da quantidade de indicadores necessários e a questão da interpretação deles; afinal, deve comunicar, ser compreensível e impactar apoiando a tomada de decisão. Quando agregados sintetizam e facilitam a comunicação; quando desagregados apresentam as especificidades e os movimentos e ajudam na tomada de decisão. Os indicadores, por vezes, concentram-se mais em descrever como medir, mas é essencial discutir como interpretá-lo, ligandoos à ação política.

O monitoramento e acompanhamento traz o desafio do custo de coleta de dado e manutenção de banco de dados no longo prazo, principalmente em países periféricos. E essa dificuldade em gerar bases de dados com confiabilidade impacta na escolha dos sistemas, como já destacado: data-driveness. 
Para que se possa mensurar é importante delimitar o subsistema comunidade, nação, empresa -, ainda que haja interdependência entre as partes e o todo, em uma visão holística do conceito. Bell e Morse (2009, p. 5) lembram da força que a delimitação político-administrativa municipal tem ganhado: "Even the idea of a sustainable city, an apparent contradiction in terms, has become so popular that prizes are now provided for those cities deemed to be the most sustainable, and indicators play a major role in this process".

Para Zachary (1995 apud BELL; MORSE, 2008, p. 83) existem quatro funções para indicadores de sustentabilidade em comunidades urbanas:

i) enabling a community to identify what is values and allowing it to prioritize those values; ii) allowing the community to hold individuals and groups accountable for acbieving goals identified by the community; iii) encouraging democracy; iv) allowing people to measure what is important and make decisions based on those results.

Por fim, retomamos os requisitos para indicadores de sustentabilidade, apresentados em Van Bellen (2006): i) os valores dos indicadores devem ser mensuráveis ou observáveis; ii) deve existir disponibilidade de dados; iii) a metodologia para a coleta e o processamento dos dados e para construção dos indicadores deve ser clara, transparente e padronizada; iv) os meios para construir e monitorar os indicadores devem estar disponíveis, incluindo capacidade financeira, humana e técnica; v) os indicadores ou grupo de indicadores devem ser financeiramente viáveis; vi) deve existir aceitação política dos indicadores no nível adequado; vii) indicadores não legitimados pelos tomadores de decisão são incapazes de influenciar as decisões. A legitimidade no processo de tomada de decisão, seja na concepção ou uso dos indicadores, aponta para a necessidade de se discutir a governança.

\section{Desafios para a governança sustentável}

Leis (1999) aponta três aspectos para pensar a governança dos desafios ambientais: i) crescente perda da soberania dos Estados-nação; ii) aumento exponencial de atores não estatais; e iii) disseminação de tecnologia de comunicação que permitem maior interação. A crise ecológica e suas causas desafiam a humanidade "[...] a encontrar soluções abrangentes e complexas que claramente transcendem as capacidades da ciência, da técnica e das instituições políticas existentes" (LEIS, 1999, p. 12). E essa ampliação de atores e instituições políticas traz à baila a discussão sobre o ambientalismo e seus atores.

Leis (1999) apresenta as três abordagens tradicionais do ambientalismo: i) como grupo de pressão; ii) como movimento social; iii) como movimento histórico. $\mathrm{Na}$ primeira vertente o movimento é 
basicamente lobby, constituindo uma perspectiva elitista e não problematiza a dimensão civilizatória. O movimento dá mais relevância às instituições de caráter técnico com capacidade de influir no sistema político. $\mathrm{Na}$ segunda vertente, novo movimento social, percebe-se o movimento como ator crítico em relação à ordem capitalista. Aqui têm destaque as abordagens mais radicais (ética e normativa), dos ecologistas, as quais se associam politicamente com a emergência dos partidos verdes. E o conflito está acima da cooperação, portanto. Já na terceira abordagem, historicamente, associa-se o modelo civilizatório atual como insustentável em longo prazo, economicamente, institucionalmente e axiologicamente. Isso implica mudanças em vários aspectos da vida social. Esta abordagem para Leis (1999, p. 36) assume o caráter complexo do movimento e dá relevância à multiplicidade de suas expressões e suas interações: “[...] enfatizando tanto a importância dos setores moderados quanto dos radicais, dos setores técnicos e dos políticos, dos não governamentais e governamentais, dos cientistas como dos empresários etc.”.

Tratando do caso nacional, desafios têm surgido para engajar o cidadão na discussão e garantir um processo de governança ambiental:

Para isso, é necessário enfrentar os obstáculos relativos à efetiva participação social, ao fomento e à utilização de capital social, aos dilemas relacionados à descentralização, entre outros fatores situados no campo da governança ambiental. Os déficits no processo de governança minaram a continuidade da AG21, que necessita de um prévio amadurecimento das relações entre governo e sociedade civil para realizar seu potencial de transformação (FONSECA, 2016, p. 326).

Pensar a sustentabilidade demanda, portanto, engajamento e responsabilidade compartilhada. Para Griffin (2010, p. 366):

Sustainability is said to require a climate of 'dialogue', 'partnership' and 'shared responsibility', rather than centralized 'command and control' policies. Shared responsibility should involve stakeholder participation and partnership between policy levels, institutions and actors. What is more, genuine sustainability must take the long term into account - it cannot be achieved within simple short-term political and economic cycles.

Griffin (2010,p.365) aponta algumas falhas na governança ambiental: ineficiências políticas, má implementação de políticas públicas, deficiências democráticas e de responsabilização e, naturalmente, problemas ambientais crescentes. Muitos dos problemas ambientais são intitulados problemas de gestão, ou "failures of governing", que para Griffin (2010, p. 365) significa: "they are blamed, inter alia, on flawed political contexts, on ineffective regulatory mechanisms, on the inappropriate scales at which policy is made and on the unaccountability of existing mechanisms for policymaking". 
Essa autora aponta para novas formas de governança ambiental, em paralelo aos instrumentos de governança institucionalizados pelo poder público:

These include public-private partnerships, regional development agencies and stakeholder panels. [...] Such arrangements sometimes function outside, or parallel to, traditional government institutions, and they are now likely to involve the participation of diverse actors, from policymakers, economic interest groups, consumer organizations and NGOs to scientists" (GRIFFIN, 2010, p. 366).

Com isso, novos modos de coordenação entre as escalas políticas e a própria noção de espaço (sistemas em subsistemas) precisam ser colocados em discussão. Mesmo com novos modos de governança e novos modos de se pensar a dimensão ambiental e as políticas públicas, Griffin (2010, p. 369) aponta como causas da falta de resultados desses instrumentos: "fall short of their anticipated outcomes due to their 'messiness', complexity, hybridity and unevenness" (GRIFFIN, 2010, p. 369).

Ao analisar elementos que constam dos fatores apresentados pela Academy of Sustainable Communities (ASC) como importantes para "Comunidades sustentáveis" (Box 1), Bell e Morse (2008) colocam a seguinte questão: afinal, o que essa lista difere das promessas políticas tradicionais? Por que chamá-las agora de sustentáveis?

\section{Quadro 1 - Fatores importantes para comunidades sustentáveis}

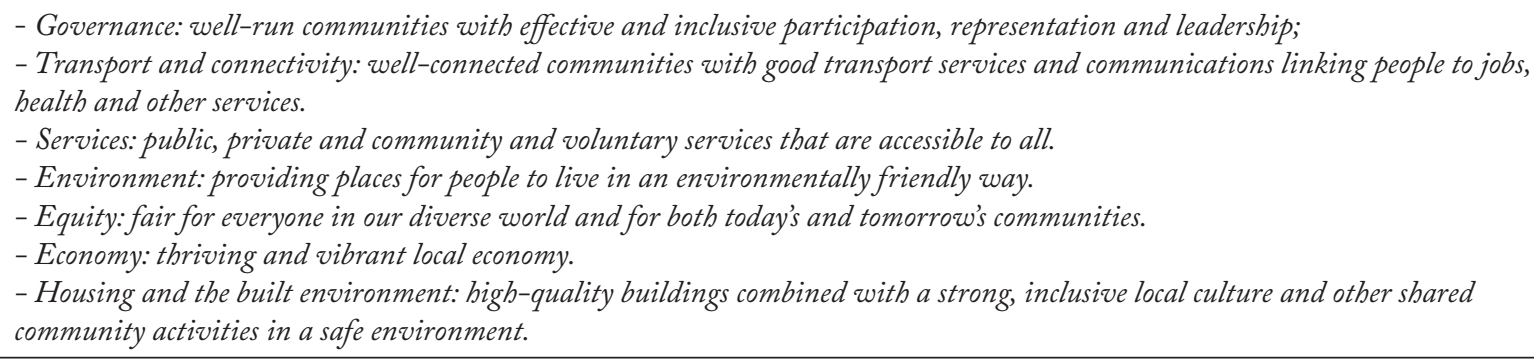

Fonte: Adaptado de Bell e Morse (2008).

Os autores, então, provocam:

The clear association of terms such as 'jobs', 'health', and 'education' with sustainability certainly provides an obvious resonance with central concerns of almost every human being and thus provides a good starting point. Indeed, it is the participative nature of sustainable city programmes that largely distinguishes them from many other initiatives to put sustainability into practice. (BELL; MORSE, 2008, p. 83).

Essa é uma estratégia para ampliar a noção de sustentabilidade, para promover legitimidade e mobilização. Nesse sentido, cabe resgatar 
o diálogo sobre mobilização que a elaboração da Agenda 21 brasileira conseguiu promover:

[...] passados mais de dez anos de sua elaboração, percebe-se que a Agenda 21 brasileira serviu mais como instrumento de mobilização, em seu período de elaboração, e como quadro referencial para a elaboração de políticas e programas voltados à promoção do desenvolvimento sustentável. Seu mérito foi, portanto, mais técnico e acadêmico, ou, ainda, de pedagogia social. (MOURA; BEZERRA, 2016, p. 104).

As críticas já apresentadas sobre a dificuldade em dar continuidade à Agenda como um processo que promova a sustentabilidade são retomadas aqui. Ou seja, a mobilização não deve se limitar à construção, mas sim engajar na expansão dos espaços de governança. E não podemos deixar de trazer aqui as críticas de ambientalistas ao "participativismo", no qual muitas decisões são tomadas e legitimadas em ambientes ditos democráticos, mas que tecnicamente impactam fortemente o meio ambiente (antropocentrismo). Ou seja, é preciso dialogar dimensões técnicas, com especialistas/pesquisadores, e dimensões políticas, democraticamente, e pensar o "compartilhamento de um projeto político" (DAGNINO, 2002).

Portanto, a construção da noção de sustentabilidade passa pelo seu monitoramento e pela avaliação, pelos indicadores, e pelo engajamento e pela legitimidade que o indicador promove, pela governança ambiental envolvendo uma diversidade de atores, incluindo movimento ambientalista e poder público.

\section{Procedimentos metodológicos}

Para atingir os objetivos propostos no desenho de pesquisa utilizamos a abordagem qualitativa, a fim de compreender o fenômeno social, operacionalizado por meio de entrevistas semiestruturadas com atores envolvidos. Optamos por entrevistar um ator engajado na proposição e gestão do programa e, para tanto, entrevistamos a coordenação de indicadores do Programa Cidades Sustentáveis, e atores de organizações da sociedade civil da Rede de Cidades Justas, Democráticas e Sustentáveis. Por isso, pela longa trajetória e acessibilidade, entrevistamos dois membros do Instituto Nossa Ilhéus (INI). O INI atua na educação para cidadania, no monitoramento social e avaliação do impacto de políticas públicas, e desde 2012 produz e articula a elaboração de indicadores de sustentabilidade, mesmo antes de se vincular ao PCS. Assim, dialogamos com a coordenação do programa nacional e uma experiência local para contribuir com a compreensão da construção e implementação dos indicadores. As entrevistas foram realizadas via Skype, duraram em torno de uma hora e foram realizadas no mês de março de 2017 (Quadro 2). 
Quadro 2 - Lista de entrevistas

\begin{tabular}{|l|c|c|}
\hline Entrevistados & Atuação & Tempo de entrevista \\
\hline Entrevistado 1 & Diretoria do Instituto Nossa Ilhéus & 1h:22min \\
\hline Entrevistado 2 & Coordenação de indicadores do PCS & $1 \mathrm{~h}: 10 \mathrm{~min}$ \\
\hline Entrevistado 3 & Consultor do Instituto Nossa Ilhéus & $1 \mathrm{~h}: 16 \mathrm{~min}$ \\
\hline
\end{tabular}

Fonte: Elaborado pelo autor (2018).

As temáticas que nortearam a condução das entrevistas, para discutir a construção e os desafios de implementação do PCS, bem como a tradução do conceito de sustentabilidade no nível local e a governança dos indicadores, foram organizadas em três grandes categorias analíticas: i) adesão ao programa; ii) construção e uso de indicadores; iii) governança de indicadores.

Quadro 3 - Categorias e elementos constitutivos

\begin{tabular}{|l|l|}
\hline Categoria & Elementos constitutivos \\
\hline Adesão ao programa & Motivaçães \\
Município & Processos \\
& Setores envolvidos \\
& Resultados/aplicação/utilização \\
& Capacidade institucional \\
\hline $\begin{array}{l}\text { Construção e uso de } \\
\text { Indicadores no }\end{array}$ & Dimensões \\
Município & Campo de aplicação \\
& Disponibilidade dos dados \\
& Coleta de dados \\
& Processamento dos dados \\
& Tradução do conceito de sustentabilidade nos indicadores \\
& Comunicação/Interface/apresentação/educação \\
\hline Governança dos & Processo de tomada de decisão (bottom-up; top-down) \\
indicadores & Estágio preparatório \\
& Avaliação constante \\
& Participação na escolha dos indicadores \\
\hline
\end{tabular}

Fonte: Elaborado pelo autor (2018).

As análises são apresentadas a partir das convergências e divergências das narrativas dos atores, dialogando os entrevistados e o estado da arte, para apresentar uma perspectiva histórica do PCS e da adesão ao programa, destacando os processos em diferentes escalas dos usos dos indicadores.

\section{Cidades sustentáveis: do conceito ao programa}

O Programa Cidades Sustentáveis (PCS) é uma realização da Rede Nossa São Paulo, Redes Social Brasileira por Cidades Justas e Sustentáveis e Instituto Ethos, desde 2011, que tem por objetivo “[...] sensibilizar, mobilizar e oferecer ferramentas para que as cidades brasileiras 
se desenvolvam de forma econômica, social e ambientalmente sustentável" (CIDADES SUSTENTÁVEIS, 2012, p. 3). No Guia GPS (2016, [s. p.]), afirma-se que o objetivo é "[...] contribuir com as equipes responsáveis nas prefeituras para desenvolver seu Plano Diretor e estabelecer Metas Estratégicas".

O PCS está estruturado em quatro linhas: i) ferramentas; ii) mobilização; iii) compromissos; e iv) benefícios para as cidades participantes. Nas ferramentas, oferecem uma agenda para a sustentabilidade, a qual está estruturada em 12 eixos temáticos, indicadores gerais associados aos eixos, indicadores mínimos a partir das cartas-compromisso de candidatos e prefeitos e banco de melhores práticas, com casos e referências nacionais e internacionais. A linha relacionada à mobilização implica impulsionar partidos e eleitores para que valorizem os candidatos comprometidos com o Programa. Firmada a Carta Compromisso, os signatários eleitos deverão promover o PCS e prestar contas das ações, a partir dos indicadores. Por fim, como benefícios para as cidades participantes, apontam:

[...] ganharão visibilidade em materiais de divulgação e na mídia, terão acesso a informações estratégicas e trocarão experiências com outras cidades, além de fazerem parte de um movimento inédito no Brasil que representa um passo a mais no processo de construção de cidades mais justas, democráticas e sustentáveis. (CIDADES SUSTENTÁVEIS, 2012, p. 3).

A agenda para a sustentabilidade, também intitulada Plataforma Cidades Sustentáveis, foi inspirada em Alborg, pacto político para o Desenvolvimento Sustentável assinado por mais de 650 municípios na Europa. Para contextualizar, trazemos algumas informações do programa europeu:

Os compromissos consideram a participação da comunidade local na tomada de decisões, a economia urbana preservando os recursos naturais, a equidade social, o correto ordenamento do território, a mobilidade urbana, o clima mundial e a conservação da biodiversidade, entre outros aspectos relevantes. (CIDADES SUSTENTÁVEIS, 2012, p. 4).

$\mathrm{Na}$ Carta das Cidades Europeias para a Sustentabilidade, realizada em Alborg na Dinamarca em 1994, destaca-se a tomada de consciência de que níveis de consumo não podem ser alcançados por todos os povos e gerações futuras, sem destruição de capital natural, firmando um compromisso das autoridades locais em partilhar a responsabilidade, à medida que possuem papel essencial nos hábitos, na produção, no consumo e nas estruturas ambientais. 
Reconhecendo a cidade como unidade capaz de gerir desequilíbrios humanos, apontam a necessidade de integrar princípios da sustentabilidade em todas as políticas e atuar a partir das especificidades locais. São destacados elementos para discussão nessa esfera: equidade social, uso sustentável do território, mobilidade urbana sustentável, responsabilidade pelo clima, prevenção de intoxicação dos ecossistemas, instrumentos de gestão urbana, autogestão no plano local e o protagonismo da sociedade com o envolvimento comunitário. Para tanto, perceberam a necessidade de engajar as autoridades locais em uma campanha para conceber planos de ação local, destacando-se o papel da Agenda 21 local. Dentre os objetivos iniciais de construção, estavam: recrutar signatários, organizar anualmente o prêmio da cidade sustentável, formular recomendações à Comissão Europeia, fornecer contribuição aos peritos, ajudar os decisores e publicar boletim (AAVV, 1994).

Dez anos depois, nos Compromissos de Alborg, são estabelecidos alguns passos, como diagnóstico da situação atual, estabelecimento de metas de modo participativo e que incorpore dados da Agenda 21 Local, compromisso político, implementação de ações e monitoramento. Assim, o Programa Cidades Sustentáveis iniciou-se com essa influência, mas ainda se adaptando à realidade brasileira, inserindo eixos temáticos, por exemplo.

Já na segunda gestão, o programa sofreu adaptação pelos Objetivos do Desenvolvimento Sustentável da ONU em sua estrutura, relacionando os eixos temáticos aos objetivos e os indicadores às metas, como veremos a seguir. Discutiremos, na sequência, o processo de adesão ao programa, os indicadores e seus eixos e, por fim, a governança dos indicadores, já que nos interessa discutir as escolhas e os processos de implementação.

A Plataforma é, portanto, uma ferramenta com o objetivo de:

- Assumir esses desafios e aceitar as responsabilidades;

- Elaborar políticas públicas para a sustentabilidade;

- Traduzir a perspectiva comum para um futuro sustentável em metas concretas de sustentabilidade e em ações integradas nos níveis locais, regionais e nacional;

- Selecionar prioridades apropriadas às realidades e necessidades locais e regionais, que deverão ter em atenção o respectivo impacto global;

- Promover processos locais e regionais participativos, no sentido de identificar metas específicas e horizontes temporais para monitorar os resultados alcançados (CIDADES SUSTENTÁVEIS, 2012, p. 4, grifos nossos).

\section{A adesão ao programa}

O processo de adesão permite compreender o funcionamento e a continuidade do programa; implica mobilização, legitimidade e governança. 
Fica evidente a importância da dimensão política na adesão ao programa cujo ciclo de gestão é relacionado ao eleitoral. O relato dos demais entrevistados sobre a utilização dos candidatos, das logos em seus materiais publicitários de campanha e do papel dos prefeitos na continuidade do compromisso, reforça esta relação.

A carta compromisso é o momento simbólico e formal em que o candidato torna-se signatário e passa a integrar o programa. Embora a prefeitura ganhe visibilidade no PCS, a assinatura depende do candidato, por tratar-se de um projeto de governo, em que o acordo renova-se a cada gestão, ainda que haja reeleição.

Os prefeitos buscam legitimidade, mostrando comprometimento com o PCS: "[...] virou um tipo de diferencial na campanha [...] poderiam se posicionar e mostrar para a sociedade civil que estavam fazendo diferente [...] é uma marca para as campanhas" (Entrevistado 3).

Foi bacana porque eles comę̧aram a disputar entre eles. Nós comę̧amos a dar visibilidade por meio de nosso site quais tinham assinado a carta compromisso [...]. Ai teve briga em município de candidato que não tinha ido ao evento de vir correndo no Institut. Nós guardamos algumas camisas, e aí eles assinaram aqui mesmo no Instituto Nossa Ilbéus. E aí a gente fazia foto, e mostrava que ele também assinou. (Entrevistado 1).

Mas além do marketing/legitimidade, os entrevistados entendem que existem outras motivações para assinar a carta-compromisso: "[...] a gente percebe que mesmo as cidades médias, nem é só as pequenas, muitas vezes elas não têm como viabilizar, porque as ferramentas são caríssimas. É um custo alto que você precisa dispor. Às vezes, precisa de consultor, né?”. (Entrevistado 2).

Nesse aspecto, é essencial o comprometimento pessoal do prefeito com o PCS, para todos os entrevistados. Quando o comprometimento do prefeito era meramente marketing político, a proposta de elaborar um plano de metas e de monitorar o município por meio dos indicadores se perdia logo no início do mandato. E aqui, os entrevistados relatam a importância da sociedade civil cobrar que os compromissos tenham continuidade e que a prefeitura elabore o plano de metas e monitore os indicadores. Isso porque o programa não prevê punição ou multa para o município que aderiu, mas não cumpriu com os compromissos.

O plano de metas deve apontar as prioridades de gestão, ações estratégicas, com indicadores e metas para a gestão pública municipal. Para elaborar o plano de metas, o Guia GPS (2016) sugere que se orientem pelos indicadores do diagnóstico para cada eixo temático, pela elaboração da Matriz Swot dos eixos, por fim, definição dos indicadores de forma participativa, para pautar a visão de futuro da cidade. Em São Paulo, é lei desde 2008 apresentá-lo. 
No entanto, o Entrevistado 2 destaca a dificuldade em se monitorar; afinal, o número de municípios que aderiram ao programa chegou na primeira gestão à 285, incluindo 22 capitais e o Distrito Federal. Foram implantados em 105 desses municípios os Observatórios de Indicadores. Nesse sentido, a equipe técnica do PCS realizou, por todas as unidades da federação com cidades signatárias, um evento, na primeira gestão, para motivar os prefeitos eleitos a integrar a rede, compartilhar experiências e dificuldades. Mas reconhece algumas das limitações do processo. Há a necessidade de avaliar regularmente o compromisso; nesse aspecto, existem planos para estabelecer uma relação mais próxima aos municípios: "A gente tá pensando em novas estratégias de monitoramento desses compromissos e monitoramento dos programas de metas que vão ser feitos também" (Entrevistado 2).

O Entrevistado 3 afirma que a dificuldade da sociedade civil em apoiar as cidades signatárias na elaboração do plano de metas: "a gente não tá dando conta de atrair todos que assinaram a carta compromisso". Atrair, nesse contexto, refere-se a contribuir, colaborar, e também cobrar, para a construção do plano de metas. $\mathrm{O}$ entrevistado reforça a fragilidade do PCS por não ter punição prevista para quem não elaborar o plano de metas: "nem quando tem a lei aprovada, muito menos quando assina a carta-compromisso".

Sendo o candidato eleito, ele recebe login, senha e uma ficha de cadastro onde deve indicar os responsáveis pelo programa. Deve indicar um responsável pelo programa (alguma secretaria, prefeito ou vice), um técnico para alimentar a plataforma e um responsável por boas práticas no município. Recomenda-se que a secretaria indicada esteja relacionada a Planejamento ou Gestão, que tenha boa transição em todas as secretarias e esteja envolvida diretamente com a tomada de decisão. A Entrevistada 2 aponta que em algumas cidades o programa fica sob responsabilidade da Secretaria de Meio Ambiente, mas dá preferência ao Planejamento, tendo em vista que quando "se fala em meio ambiente a população vê como inimigo. Meio ambiente é o pessoal chato".

O Entrevistado 3 relatou um movimento para: "Criação de uma Secretaria do Verde e de Planejamento [...], uma secretaria que coordena o planejamento integrado da ação das outras secretarias. E ela ajuda muito a fazer a amarração entre as diferentes secretarias". O Secretário de Meio Ambiente fica, então, com uma Coordenação ou Diretoria na Secretaria de Planejamento, a depender da estrutura. Em Ilhéus, leva o nome de Secretaria de Planejamento e Desenvolvimento Sustentável.

Os resultados do Programa para o Entrevistado 1 ainda são "[...] muito tênues. A melhoria que aconteceu foi a melhoria que aconteceu porque tinha que acontecer a partir dos programas mesmos, da politica pública de governo, né? Que vem avançado naturalmente. Nada que tenha sido impactado diretamente pelo plano de metas ainda". Nesse ponto, apesar de não ter ainda 
resultados diretos na implementação de políticas públicas, é possível ver alguns resultados no próprio desenho de estruturas nos municípios. Alguns questionamentos que devem ser postos: o verde ganhou relevância e será um elemento central para a tomada de decisão ou ficou de vez submisso à "agenda marrom"?

Dentre os setores destacados no processo de adesão e continuidade do programa, foram citadas nas entrevistas as seguintes organizações: Rede de Cidades Justas e Democráticas; as organizações da sociedade civil em geral; as universidades; o Sebrae; o Ministério Público Federal e Estadual; as redes e associações de municípios e prefeitos. Apontaremos algumas peculiaridades citadas pelos entrevistados de Ilhéus sobre a adesão ao programa e a capacidade institucional, a partir da aproximação com as universidades e o Sebrae.

[...] para que os professores da universidade usem a nossa plataforma no trabalho deles. Com isso a gente garante que esses indicadores serão monitorados com mais intensidade pela sociedade civil nos próximos quatro anos. O fato de ser 26 municípios também permite comparaçôes e aumenta um pouco o escopo: a gente tem mais sociedade civil, né? [...] A gente pretende fazer agora, junto com o Sebrae. O Sebrae tem interesse em promover, em alguns municípios aqui do Sul da Bahia, a lei da micro e pequena empresa [...]. A gente vai também trabalhar na elaboração da lei do plano de metas nesses municípios. (Entrevistado 3).

Portanto, percebe-se que, para ampliar a capacidade institucional, as organizações da sociedade civil estabelecem parcerias e atuam com caráter propositivo. Em sentido amplo, essa capacidade institucional depende, fortemente, do comprometimento individual dos prefeitos, ao mesmo tempo em que depende da colaboração da sociedade civil. No entanto, até que ponto essa "dependência" do prefeito permite que se estabeleçam metas relevantes e se mensure indicadores importantes para a sociedade civil?

\section{Indicadores municipais}

Nesta seção discutiremos os indicadores em si, sua composição, campo de aplicação, coleta e processamento, e comunicação. Para entender o PCS, é necessário levantar sua história e suas influências. A influência de Aalborg na primeira gestão aponta para o modelo de funcionamento do programa. Com a vinculação aos ODS, o PCS busca aproximar a dimensão local-global da sustentabilidade.

A primeira versão dos indicadores do PCS foi elaborada por um grupo de trabalho de indicadores, com várias organizações da Rede Nossa São Paulo, para definir e escolher quais seriam acompanhados, "[...] esse grupo, ao longo de meses, foi pensando quais indicadores importantes para serem 
levantados dentro de cada eixo que o programa trabalha e a viabilidade de alguns indicadores, porque, às vezes, a gente escolhe muitas coisas, mas depois não tem viabilidade de coleta depois" (Entrevistado 2). Nessa primeira gestão, foram propostos 100 indicadores básicos e 300 gerais, que contemplavam os básicos. A prefeitura tinha esse número mínimo, e, se o município fosse menor, tinha uma redução de 15 indicadores, aproximadamente, e os indicadores gerais a cidade poderia escolher se conseguia acompanhar ou não a partir do seu interesse.

Para a segunda gestão, decidiu-se aproximar dos 17 Objetivos de Desenvolvimento Sustentável, lançados na Rio+20, em 2012, como esforço para melhorar qualidade de vida, erradicar a pobreza e promover o desenvolvimento sustentável. Foram lançadas 169 metas e 231 indicadores globais, para serem adaptados às realidades nacionais. Constituem o eixo central da Agenda 2030, centrada nas dimensões econômica, social e ambiental, que entraram em vigor em 2016.

O Guia Gestão Pública Sustentável (GPS) apresenta de forma detalhada os eixos, a aproximação com os ODS, listagem de indicadores com descrição, método de cálculo, fonte e meta referência. Apresentamos, então, no Quadro 4, uma aproximação entre os 12 eixos do programa, com seu número de indicadores já na segunda gestão, e os 17 ODSs. Essa relação apresenta um primeiro desafio de tradução: do global ao local. 
Quadro 4 - Eixos e objetivos do PCS

\begin{tabular}{|c|c|c|c|}
\hline Eixo & Objetivo geral & ODS & $\begin{array}{l}\text { Número de } \\
\text { indicadores }\end{array}$ \\
\hline Governança & $\begin{array}{l}\text { Fortalecer os processos de decisão com a promoção de instrumentos da } \\
\text { democracia participativa, fomentando a igualdade em suas múltiplas } \\
\text { dimensões. }\end{array}$ & $\begin{array}{c}5,10 \\
16\end{array}$ & 31 \\
\hline $\begin{array}{l}\text { Bens naturais e } \\
\text { comuns }\end{array}$ & $\begin{array}{l}\text { Assumir plenamente as responsabilidades para proteger, preservar e } \\
\text { assegurar o acesso equilibrado aos bens naturais comuns. }\end{array}$ & $\begin{array}{l}2,6,11 \\
12,14 \\
15\end{array}$ & 21 \\
\hline $\begin{array}{l}\text { Equidade, justiça } \\
\text { social e cultura da } \\
\text { paz }\end{array}$ & $\begin{array}{l}\text { Promover comunidades inclusivas e solidárias, por meio de ações que } \\
\text { melhorem a distribuição de riqueza, diminuam a violência e ampliem o } \\
\text { acesso à informação. }\end{array}$ & $\begin{array}{l}1,3,5 \\
9,10 \\
11,16\end{array}$ & 43 \\
\hline $\begin{array}{l}\text { Gestão local para a } \\
\text { Sustentabilidade }\end{array}$ & $\begin{array}{l}\text { Implementar uma gestão responsável, participativa e eficiente que envolva } \\
\text { as etapas de planejamento, execução e avaliação. }\end{array}$ & $\begin{array}{l}11,12 \\
16,17\end{array}$ & 8 \\
\hline $\begin{array}{l}\text { Planejamento e } \\
\text { desenho urbano }\end{array}$ & $\begin{array}{l}\text { Reconhecer o papel estratégico do planejamento e do desenho urbano na } \\
\text { abordagem sistêmica das questões ambientais, sociais, econômicas, culturais } \\
\text { e da saúde, para benefício de todos. }\end{array}$ & 11 & 9 \\
\hline $\begin{array}{l}\text { Cultura para a } \\
\text { sustentabilidade }\end{array}$ & $\begin{array}{l}\text { Desenvolver políticas culturais que respeitem e valorizem a diversidade } \\
\text { cultural, o pluralismo e a defesa do patrimônio natural constituído e } \\
\text { imaterial, ao mesmo tempo em que promovam a preservação da memória } \\
\text { e a transmissão das heranças naturais, culturais e artísticas, assim como } \\
\text { incentivem uma visão aberta de cultura em que valores solidários, } \\
\text { simbólicos e transculturais estejam ancorados em práticas dialógicas, } \\
\text { participativas e sustentáveis. }\end{array}$ & 4,11 & 8 \\
\hline $\begin{array}{l}\text { Educação para a } \\
\text { Sustentabilidade e } \\
\text { Qualidade de vida }\end{array}$ & $\begin{array}{l}\text { Integrar, na educação formal e não formal, conhecimentos, valores e } \\
\text { habilidades para a construção de um modo de vida sustentável. }\end{array}$ & 4 & 37 \\
\hline $\begin{array}{l}\text { Economia Local, } \\
\text { Dinâmica, Criativa } \\
\text { e Sustentável }\end{array}$ & $\begin{array}{l}\text { Apoiar e criar condições para uma economia local dinâmica e criativa, } \\
\text { que garanta o desenvolvimento e a geração de empregos sem prejudicar o } \\
\text { ambiente, levando em conta a economia verde como eixo estratégico. }\end{array}$ & $\begin{array}{c}2,7,8 \\
9,12\end{array}$ & 35 \\
\hline $\begin{array}{l}\text { Consumo } \\
\text { Responsável e } \\
\text { Opções de estilo } \\
\text { de vida }\end{array}$ & $\begin{array}{l}\text { Adotar e proporcionar o uso responsável e eficiente dos recursos e } \\
\text { incentivar um padrão de produção e consumo sustentáveis. }\end{array}$ & $\begin{array}{l}6,7,11 \\
12\end{array}$ & 15 \\
\hline $\begin{array}{l}\text { Melhor mobilidade, } \\
\text { menos tráfego }\end{array}$ & $\begin{array}{l}\text { Promover a mobilidade sustentável, reconhecendo a interdependência entre } \\
\text { os transportes, a saúde, o ambiente e o direito à cidade. }\end{array}$ & 3,11 & 13 \\
\hline $\begin{array}{l}\text { Ação local para a } \\
\text { saúde }\end{array}$ & Proteger e promover a saúde e o bem-estar dos cidadãos. & $2,3,5$ & 29 \\
\hline Do local ao global & $\begin{array}{l}\text { Assumir as responsabilidades globais pela paz, justiça, equidade, } \\
\text { desenvolvimento sustentável, proteção ao clima e à biodiversidade. }\end{array}$ & $\begin{array}{c}7,11 \\
13\end{array}$ & 11 \\
\hline
\end{tabular}

Fonte: Adaptado de Guia GPS (2016).

Para essa segunda edição do PCS, a coordenação afirma:

A gente levantou os indicadores de desenvolvimento sustentável que - IBGE trabalha, indicadores que a gente trabalhava, indicadores que estavam sendo propostos no global, indicadores que estavam sendo 
propostos no Brasil para pensar essas metas dos ODSs. A gente fez um grande levantamento e, a partir disso, a gente achou que 100 indicadores não iam contemplar toda diversidade que a gente tem dentro dos ODSs. Os indicadores acabaram crescendo de número para 260. (Entrevistado 2).

Percebemos, no entanto, que essa expansão de indicadores pode, ao mesmo tempo em que amplia a possibilidade de aprofundar em alguns aspectos, esconder algumas dimensões de sustentabilidade. Trazemos a experiência de aplicação do PCS em Ilhéus, para compreender como as escolhas, a coleta e o processamento de dados podem trazer uma noção própria de sustentabilidade.

Lembramos que o campo de aplicação concentra-se no município, mas o sistema do PCS permite regionalizar os dados. O Entrevistado 3 discute a necessidade de territorializar os dados e permitir "zooms" no sistema. Em São Paulo, por exemplo, os indicadores já estão sendo aprofundados com dados intraurbanos, pelas subprefeituras. Assim, a Rede Nossa São Paulo publicou o Mapa das Desigualdades, a partir da comparação dos dados dentro da própria cidade.

Ilhéus iniciou a discussão sobre indicadores em 2008, antes do surgimento do PCS, e aprovou o plano de metas. $\mathrm{O}$ artigo 73 da lei orgânica de Ilhéus estabelece que em 90 dias o prefeito eleito deve apresentar o plano de metas. O lançamento oficial do PCS em Ilhéus ocorreu em 2012 na Câmara de Vereadores. Em parceria com o Teatro Popular de Ilhéus, realizou-se o projeto "A Ilhéus que queremos: a cidade é movida pela cultura”, com o objetivo de estudar três momentos: i) a Ilhéus que herdamos; ii) a Ilhéus que temos; iii) a Ilhéus que queremos. Primeiramente discutiu-se o aspecto histórico da região, culturalmente e economicamente. No segundo momento, para compreender "a Ilhéus que temos", o INI contratou uma empresa de consultoria para fazer o levantamento de indicadores do município comparando Ilhéus com municípios do mesmo porte e realizando o levantamento de dados intraurbanos, dividindo o município em 13 áreas "[...] pra entender melhor o que acontecia em cada uma dessas áreas" (Entrevistado 1). Esse sistema de indicadores não levava o termo sustentabilidade. Foram levantados 70 indicadores sobre a situação da cidade e o desempenho das políticas públicas, em diversas áreas - "Saúde, Educação, Violência, Trabalho e Renda, Juventude, Trânsito, Condições de Moradia e Pessoas com Deficiência” (INI, 2017).

Para discutir a "Ilhéus que queremos", adentraram ao programa da Rede de Cidades e seus eixos. A coleta de dados foi realizada apenas em 2012 pelo INI. Mas, nessa primeira gestão do PCS, em Ilhéus pouco se avançou na coleta e monitoramento de indicadores, já que a prefeitura, ainda que tenha assinado, não coletou os dados.

Tendo essas dificuldades em cobrar que a prefeitura disponibilizasse os dados, o INI se aproximou da Universidade. "Nós conseguimos fazer um 
convênio, acordo de cooperação técnica" (Entrevistado 1). Para isso, expandiram a área de abrangência para que coletassem dados no recorte administrativo do Território Litoral Sul - 26 municípios - e, com o apoio do Instituto Arapyaú, coletaram indicadores para os 26 municípios entregando em 2016 às prefeituras.

Os indicadores da fase de teste elaborados pelo INI, por meio de contratação de consultoria externa, estão estruturados a partir de sete eixos. Para a escolha dos sete, dentre os 12 , "Nós escolhemos quais eram os mais importantes para levantar. [...] Esses nós já demos preenchidos para eles" (Entrevistado 1). Ressaltamos que esses indicadores foram selecionados também por acessibilidade e viabilidade, portanto, dados secundários.

Quadro 5 - Indicadores coletados em Ilhéus

\begin{tabular}{|c|c|}
\hline Eixo & Indicadores \\
\hline Bens naturais e comuns & $\begin{array}{l}\text { 1. Domicílios atendidos por rede de esgoto ou fossa séptica } \\
\text { 2. Domicílios com acesso à água encanada }\end{array}$ \\
\hline $\begin{array}{l}\text { Equidade, justiça social e } \\
\text { cultura da paz }\end{array}$ & $\begin{array}{l}\text { 1. Agressões a crianças e adolescentes, por } 10 \text { mil habitantes de até } 17 \text { anos de idade; } \\
\text { 2. Agressões a mulheres, por } 10 \text { mil mulheres residentes } \\
\text { 3. Agressões: violência sexual, por } 100 \text { mil habitantes } \\
\text { 4. Estupros, por } 100 \text { mil habitantes } \\
\text { 5. Homicídio doloso, por } 100 \text { mil habitantes } \\
\text { 6. Internações por agressões, por } 100 \text { mil habitantes } \\
\text { 7. Proporção da população em situação de pobreza - } \% \\
\text { 8. Proporção da população em situação de pobreza extrema - \% } \\
\text { 9. Índice de desenvolvimento humano municipal (IDH-m) } \\
\text { 10. Índice de gini (desigualdade de renda) }\end{array}$ \\
\hline $\begin{array}{l}\text { Educação para a } \\
\text { Sustentabilidade e } \\
\text { Qualidade de vida }\end{array}$ & $\begin{array}{l}\text { 1. Abandono no ensino fundamental da rede pública } \\
\text { 2. Abandono no ensino médio da rede pública } \\
\text { 3. Alfabetização - alunos do } 3^{\circ} \text { ano do ensino fundamental com nível adequado de proficiência } \\
\text { em leitura - rede pública (\%) } \\
\text { 4. Distorção idade-série no ensino fundamental na rede pública } \\
\text { 5. Distorção idade-série no ensino médio na rede pública } \\
\text { 6. Escolas públicas de educação básica com acessibilidade (\%) } \\
\text { 7. Escolas públicas de ensino fundamental com acesso à internet banda larga (\%) } \\
\text { 8. Escolas públicas de ensino fundamental com biblioteca ou sala de leitura (\%) } \\
\text { 9. IDEB da rede pública - anos finais } \\
\text { 10. IDEB da rede pública - anos iniciais } \\
\text { 11. Matrículas no ensino fundamental em tempo integral - rede pública (\%) } \\
\text { 12. Professores da educação básica com ensino superior - rede pública (\%) } \\
\text { 13. Proporção da população com ensino superior ( } 25 \text { anos ou mais) - \% } \\
\text { 14. Reprovação no ensino fundamental da rede pública } \\
\text { 15. Reprovação no ensino médio da rede pública } \\
\text { 16. Taxa de analfabetismo ( } 15 \text { anos ou mais) - } \% \\
\text { 17. Taxa de frequência escolar }(0 \text { a } 3 \text { anos) - } \% \\
\text { 18. Taxa de frequência escolar ( } 15 \text { a } 17 \text { anos) - } \% \\
\text { 19. Taxa de frequência escolar }(4 \text { a } 5 \text { anos) - } \% \\
\text { 20. Taxa de frequência escolar }(6 \text { a } 14 \text { anos) - } \% \\
\text { 21. Trabalho infantil - taxa de atividade } 10 \text { a } 14 \text { anos (\%) }\end{array}$ \\
\hline
\end{tabular}




\begin{tabular}{|c|c|}
\hline Eixo & Indicadores \\
\hline $\begin{array}{l}\text { Economia Local, } \\
\text { Dinâmica, Criativa e } \\
\text { Sustentável }\end{array}$ & $\begin{array}{l}\text { 1. Formalização do trabalho (\%) } \\
\text { 2. Jovens de } 15 \text { a } 29 \text { anos que não estudam nem trabalham }(\%) \\
\text { 3. PIB municipal (R } \$ \text { mil, correntes) } \\
\text { 4. PIB municipal per capita (R\$ correntes) } \\
\text { 5. Proporção da população com renda per capita de até } 1 / 4 \text { do salário mínimo (\%) } \\
\text { 6. Taxa de desocupação (18 a } 24 \text { anos) }-\% \\
\text { 7. Taxa de desocupação (18 anos ou mais) - } \%\end{array}$ \\
\hline $\begin{array}{l}\text { Consumo R. e Opções de } \\
\text { estilo de vida }\end{array}$ & 1. Consumo de água per capita $\left(\mathrm{m}^{3}\right)$ \\
\hline $\begin{array}{l}\text { Melhor mobilidade, } \\
\text { menos tráfego }\end{array}$ & $\begin{array}{l}\text { 1. Internações por acidente de trânsito, por } 100 \text { mil habitantes } \\
\text { 2. Mortes por acidente de trânsito, por } 100 \text { mil habitantes } \\
\text { 3. Mortes por atropelamento, por } 100 \text { mil habitantes }\end{array}$ \\
\hline Ação local para a saúde & $\begin{array}{l}\text { 1. Baixo peso ao nascer (\%) } \\
\text { 2. Curetagem pós-abortamento, por mil mulheres entre } 15 \text { e } 39 \text { anos } \\
\text { 3. Esperança de vida ao nascer (anos) } \\
\text { 4. Gravidez na adolescência - partos com idade da mãe até } 19 \text { anos (\%) } \\
\text { 5. Internações hospitalares por infecção respiratória aguda (ira) - por mil crianças de } 0 \text { a } 4 \text { anos } \\
\text { 6. Leitos hospitalares por mil habitantes } \\
\text { 7. Mortalidade câncer colo do útero (por } 100 \text { mil mulheres com } 30 \text { anos ou mais) } \\
\text { 8. Mortalidade infantil (por mil nascidos vivos) } \\
\text { 9. Mortalidade neonatal precoce (por mil nascidos vivos) } \\
\text { 10. Mortalidade neonatal tardia (por mil nascidos vivos) } \\
\text { 11. Mortalidade por doenças do aparelho circulatório, por } 10 \text { mil hab. } \\
\text { 12. Mortalidade precoce por doenças crônicas não transmissíveis (dcnt) - por } 100 \text { mil pessoas de } \\
\text { 13. Morta } 70 \text { anos } \\
\text { 14. Partos em que a mãe teve ao menos sete consultas pré-natal (\%) } \\
\text { 15. Partos normais (\%) } \\
\text { 16. Óbitos fetais (por mil nascidos vivos) }\end{array}$ \\
\hline
\end{tabular}

Fonte: Elaborado pelo autor (2018).

Os indicadores permitem monitorar as políticas públicas. Destacamos que algumas prefeituras trabalham com consultorias, enquanto outras com universidades, para a coleta de dados, mas para a coordenação do PCS esse número é menor, "a maioria é interno mesmo" (Entrevistado 2). Aprofundaremos na próxima seção o processo de governança, da escolha dos indicadores e participação da sociedade civil nesse processo.

Desde já, percebemos que os indicadores escolhidos pela viabilidade apontam para a escassez de indicadores na dimensão ambiental. A visão construída pelos entrevistados é de que existem muitos desafios no aprimoramento dos indicadores para que comunique melhor, para que sejam trazidos elementos relevantes para a sustentabilidade e para que a gestão pública municipal esteja atenta às temáticas da sustentabilidade. Mas, os atores estão cientes dos desafios de se aprofundar e resgatar indicadores da dimensão ambiental.

Então, lembramos que um dos grandes desafios é a coleta de dados, seguida pela confiabilidade deles: "É um desafio gigante obter esses dados, ter confiabilidade desses dados, os que são primários têm um custo muito alto de 
coleta. Então, é algo que não é simples de manter" (Entrevistado 3). Mas uma das posturas do PCS é embora alguns dados sejam difíceis de coletar, é necessário que eles estejam no corpo de indicadores para que sirvam como incentivo para a coleta e apontem para dimensões importantes: "[...]alguns indicadores que eu acho que eles são ainda muito difíceis de serem medidos. Mas, eu acho que é importante essa discussão dentro do municipio de como fazer isso. Então, eles foram inseridos até com essa finalidade de incentivar os municípios a pensar sobre isso" (Entrevistado 2).

Ainda que a proposta do programa seja "[...] que tenha uma coisa fácil, que seja fácil de usar, por isso também os guias, porque, se for muito difícil, as cidades não vão usar" (Entrevistado 2), o Entrevistado 3 relata que sente "[...] dificuldade em utilizar a plataforma de indicadores. Então, eu fico pensando o público mais leigo. A gente vê, por exemplo, que a mídia local não dá conta, sabe? Salvo raras exceçôes, não consegue transformar esses indicadores em pauta. Não consegue traduzir esses indicadores em conceitos e refletir sobre o município" (Entrevistado 3). E esse é um desafio importante: comunicar e traduzir uma visão de sustentabilidade. Apesar de nosso objetivo não ser apontar as causas, o que estaria além da proposta deste artigo, consideramos, aqui, necessário refletir mais uma vez sobre a quantidade de indicadores, de dimensões e a postura de não agregar os dados.

Além disso, como a escolha dos indicadores é feita individualmente, daremos destaque a duas questões levantadas pelos atores: i) dificuldade em comparar os eixos entre municípios, já que nem todos coletam os mesmos indicadores e não se tem um índice agregado; ii) escolha dos indicadores com os dados que já estão disponíveis em outras bases de dados.

Esse é um dos desafios em comunicar bem e trazer novos indicadores. Nessesentido, esbarramos nos desafios apontados por Meadows: superagregação e data-driveness. Ainda que aqui não seja o caso de superagregação, já que os dados não são agregados em índices, a dificuldade no número de indicadores em comunicar, virar pauta, traduzir um conceito de sustentabilidade claro fica aquém do esperado: "Não tem tipo um IDH que consolida tudo isso num 'numerozinho' fácil de entender" (Entrevistado 3). No entanto, como ponto forte, existe o controle do plano de metas, em que cada meta tem um indicador para controle e monitoramento.

Dentre os desafios de coleta e processamento de dados, o Entrevistado 2 destaca: “A gente não tem uma padronização para dados". E, para coletar um dado, muitas vezes é preciso checar dados em duas secretarias, com dados que não conversam, não estão na mesma escala. Além disso, em função da falta de confiabilidade dos dados: "[...] muitas vezes a gente não consegue ter certeza de porque ele variou tanto, né? Se ele variou muito porque agora a gente tá registrando direito, se ele variou muito porque tá aumentando muito. A mesma coisa pra diminuir" (Entrevistado 2). 
O monitoramento dos indicadores é feito pela evolução dos dados ao longo do tempo, para acompanhamento de políticas públicas, principalmente. Enquanto outros indicadores de processo procuram "[...] ver se a cidade tem ou não tem alguma coisa [...], e também a gente trabalhar na gestão passada com referências [...], agora a gente tá trabalhando todas associadas às metas dos ODS" (Entrevistado 2).

Percebemos avanços para uma cultura de dados e para uma gestão de monitoramento e diagnósticos: "[...] principalmente assim, tem umas coisas ambientais que são muito dificeis, até a gente trabalhava com dados de medição de particulas, PM10, PM2.5, que eram coisas muito difíceis para município pequeno" (Entrevistado 2).

Ainda que limitados hoje "estão além de qualquer ferramenta de gestão que havia antes [...] a gente já tem as tendências", relata o Entrevistado 3. Entre os principais usuários, além da sociedade civil organizada, os atores citam as universidades e os pesquisadores. "E as prefeituras que usam e levantam os indicadores, elas percebem que isso é uma coisa que de fato ajuda no planejamento da cidade, sabe? Porque, às vezes, ela não tinha nem o conhecimento de como estava o município" (Entrevistado 2).

Cabe também discutir a integração dos usuários para além do uso e da comunicação final dos indicadores. Nesse sentido, na próxima seção apresentaremos os resultados quanto à governança dos indicadores.

\section{Governança dos indicadores}

O processo de escolha do conjunto de indicadores propostos pelo PCS foi realizado por um grupo de trabalho internamente na Rede Nossa São Paulo, assim como sua revisão. No entanto, os próprios municípios podem propor indicadores específicos, mais aderentes à realidade local. Se por um lado para o processamento isso dificulta comparabilidade com outros municípios, por outro ajuda a aproximar a comunidade da discussão, para que os indicadores façam sentido localmente.

Destacamos o processo liderado pelo INI para a sugestão de indicadores para a prefeitura nessa segunda gestão. O Instituto Nossa Ilhéus realizou em parceria com o Teatro Popular de Ilhéus o "Improviso Oxente" no ano de 2016, uma roda de conversas com especialistas que, para os candidatos, foi um espaço para pré-candidatura, de debates sobre sustentabilidade. Os debates tinham o objetivo de discutir os eixos do Programa Cidades Sustentáveis com especialistas da área e, ao final da exposição, os facilitadores projetavam os indicadores do PCS. Com isso, a sociedade civil presente se posicionava e escolhia os indicadores que julgava mais relevantes, podendo inclusive sugerir outros para além dos já existentes, para "eleger quais que eles gostariam de ver acompanhados" (Entrevistado 3). 
A equipe do Instituto, então, produziu um documento condensando as escolhas da sociedade civil nesse evento e entregaram aos candidatos. Percebemos a importância da sociedade civil para participar e coordenar a escolha dos indicadores e desempenhar o controle social, cobrando a inserção de dados; mas, sobretudo, participando do processo de seleção/ escolha. Ao final dos 17 debates, entregam para os prefeitos todos os indicadores considerados prioritários pela sociedade civil, inclusive alguns que não estavam listados no Guia.

Entramos, então, no diálogo sobre a participação no processo de construção dos indicadores. Por um lado, identificamos que o engajamento nesse processo da formulação pode levar a sociedade a refletir sobre o local e que o próprio processo de discussão fortalece um ambiente de sensibilização e educação ambiental. Importa que a sociedade se aproprie dessa discussão, tanto pela importância para a sustentabilidade, quanto para compreender melhor a realidade local. Participam desse momento especialistas, com uma perspectiva técnica, e cidadãos, democratizando a escolha. A escolha é para pensar o diagnóstico da cidade, aquilo que é prioridade, aquilo que se quer para o futuro.

Além disso, a aproximação da universidade e da sociedade civil organizada para a elaboração e revisão dos indicadores ajuda a legitimar o processo: "Você acima de tudo tem que ser de fato apartidário. Tem que criar essa credibilidade. Tem que estar junto, para essa credibilidade ser maior, da academia. Sem a academia não consegue, é muito mais desafiador. A academia dá uma legitimidade ao processo muito maior" (Entrevistado 1). Lembramos que "A legitimidade é elemento de importância fundamental na construção de sistemas de indicadores" (VAN BELLEN, 2006, p. 53). Portanto, o aspecto técnico e político andam juntos aqui.

Dentre os desafios atuais para o Entrevistado 3, estão: "como a sociedade civil se apropria desses indicadores para cobrar o poder público" e "como o poder público (e o público) consegue operar (e monitorar) utilizando esses indicadores".

\section{Considerações finais}

Neste artigo apresentamos o processo de construção e implementação dos indicadores do Programa Cidades Sustentáveis, discutindo desde a adesão até a governança do programa. Procuramos centrar a discussão nos indicadores para além dos números, destacando sua construção, problematizando as escolhas, bem como a comunicação dos indicadores. Para tanto, ampliamos a discussão para além do engajamento e da participação popular, centrando-nos em processos de tradução da sustentabilidade nos indicadores para nível local, sua governança, e os principais desafios de implementação. 
O Programa Cidades Sustentáveis traz para a gestão pública o desafio de utilizar os indicadores como instrumento de gestão e governança, aproximando a sociedade civil da implementação e do acompanhamento de políticas públicas, pelo plano de metas. Ainda que existam dificuldades quanto à coleta, ao tratamento e à agregação, à consolidação em índice, por exemplo, o PCS contribui para que os indicadores sejam vistos como ferramentas de gestão/monitoramento e de governança/participação no setor público. O destaque do Programa é dado para o plano de metas para a gestão municipal, que parece ser o ator principal do Programa, sendo os indicadores um meio para realizar o diagnóstico e o acompanhamento do plano.

Não podemos deixar de pontuar e questionar duas das principais limitações no processo de escolha e governança dos indicadores: i) data driveness como condutor do processo; ii) a dimensão ambiental/ecológica encoberta no amplo debate. As dificuldades de implementação (qualidade dos dados, acesso aos dados, data driveness, confiabilidade, escassez de bases, custo de coleta dos dados primários) estão presentes na realidade dos municípios. A orientação por dados já existentes pode fadar o programa a deixar de medir aquilo que importa. Nesse sentido, além da dificuldade de acesso a dados para dimensão ambiental, ela parece escondida nos 12 eixos. Nesse aspecto, resgatamos o comentário do Entrevistado 3: "Eu diria que os problemas são tão grandes que nem deu tempo de chegar ainda na questão dos bens naturais e comuns. Tem uma questão de geração de renda [...] as pessoas estão longe pensar desmatamento, por exemplo". Ou seja, parece que, mais uma vez, a dimensão ambiental é secundária, frente à econômica.

A carta-compromisso apresenta-se como um instrumento político de adesão, mas com dificuldade em garantir continuidade ao processo de coletar e disponibilizar os dados. Orienta muito mais para o plano de metas e para os indicadores como um meio. Nesse aspecto, ao olhar para o modelo e para as dimensões concordamos com Bell e Morse (2004) em questionar: o que isso difere de um programa intitulado "excelência em gestão pública?". Não queremos entrar na discussão "qualidade e excelência”, mas apontar para o vazio conceitual que o termo sustentabilidade pode tomar. Ou ainda, nessas noções difusas, o termo sustentabilidade estaria sendo ressignificado ou tornando-se meramente subsidiário e sem significado próprio?

Destacamos a importância da sociedade civil para a continuidade do programa, por meio da governança dos indicadores - desde sua definição até sua utilização -, o que engloba, também, o monitoramento para continuidade do programa. Os entrevistados destacam que, nessa interlocução com governo, a sociedade pode, por meio da governança democrática, participar e exigir que se dê continuidade na manutenção de indicadores voltados ao interesse público. 
Entendemos que a quantidade de indicadores e a falta de agregação dos dados, inclusive nos eixos, dificulta a comunicação. Os 260 indicadores ajudam no acompanhamento e na comparabilidade ao longo do tempo e servem como sugestão daquilo que as prefeituras deveriam monitorar. Por outro lado, destacamos que se agregado, hoje, o indicador poderia esconder ainda mais a dimensão dos "bens e recursos naturais". Ou seja, até que ponto os 260 indicadores ou o índice a partir dele poderia ajudar a traduzir um conceito de sustentabilidade?

Entendemos como principal contribuição do programa aos municípios a possibilidade de compor bases de dados, aproximar a comunidade da discussão das políticas públicas pelo monitoramento de indicadores - ainda que o acesso tenha se concentrado mais no terceiro setor e nas universidades. Além disso, os indicadores de sustentabilidade são atrelados ao plano de metas para orientar a gestão, trazer informações para tomada de decisão. Apesar de todas as dificuldades, tem sido um processo importante para consolidar uma "cultura" de dados, para criar bases e séries históricas, que, nesse ponto, ainda estamos em um processo embrionário, e consolidar o protagonismo da sociedade civil organizada em espaços de governança democrática, apoiada por indicadores para accountability. Por fim, esperamos que o PCS não repita os passos da Agenda 21 Local e adote uma visão processual para que o Programa tenha continuidade e possa ser, continuamente, aprimorado. Desse modo, a contribuição deste artigo, ainda que modesta, está na centralidade dos processos de construção e implantação dos indicadores, problematizando tais aspectos.

\section{Referências}

AAVV. Carta das Cidades Europeias para a Sustentabilidade - Carta de Aalborg. I Conferência Europeia sobre Cidades Sustentáveis. Aalborg: [s. n.], 1994.

ANDION, C. Por uma nova interpretação das mudanças de paradigma na administração pública. Cadernos EBAPE.BR, v. 10, n. 1, p. 1-19, 2012.

BELL, S.; MORSE, S. Sustainability indicators: measuring the immeasurable? 2. ed. London: Earthscan, 2008.

CIDAdes SustentáVEIS. Programa Cidades Sustentáveis. Cidades Participantes. 2012. Disponível em: http://www.cidadessustentaveis.org.br. Acesso em: 10 fev. 2017.

DAGNINO, E. (Org.). Sociedade Civil e Espaços Públicos. São Paulo: Paz \& Terra, 2002.

DAHL, A. L. The big picture: comprehensive approaches. In: MOLDAN, B.; BILHARZ, S. (Ed.). Sustainability indicators: Report of the project on indicators of sustainable development. Chichester: John Willey \& Sons Ltda., 1997.

FONSECA, I. F. A Retórica da Boa Governança: as Agendas 21 locais no Brasil. In: MOURA, A. M. M. (Org.). Governança Ambiental no Brasil: instituições, atores e políticas públicas. Brasília: IPEA, 2016. 
GUIA GPS. Guia de Gestão Pública Sustentável: atualizado com os ODSs. 2016. Disponível em: http://www.cidadessustentaveis.org.br. Acesso em: 10 fev. 2017.

GRIFFIN, L. Governance innovation for sustainability: Exploring the tensions and dilemmas. Environmental Policy and Governance, v. 20, p. 365-369, 2010.

KEINERT, T. M. M. Administração pública no Brasil: crises e mudanças de paradigmas. Annablume, 2000.

LEIS, H. R. A modernidade insustentável: as críticas do ambientalismo à sociedade contemporânea. Petrópolis: Vozes; Florianópolis: Ed. da UFSC, 1999.

LEME, T. N. Governança ambiental no nível municipal: instituições, atores e políticas públicas. In: MOURA, A. M. M. (Org.). Governança Ambiental no Brasil: instituições, atores e políticas públicas. Brasília: IPEA, 2016. p.

LUCHMANN, L. H. L. Democracia deliberativa: sociedade civil, esfera pública e institucionalidade. Cadernos de Pesquisa, v. 33, p.1-38, 2002.

MALHEIROS, T. F.; PHLIPPI JR., A.; COUTINHO, S. M. V. Agenda 21 nacional e indicadores de desenvolvimento sustentável: contexto brasileiro. Saúde soc., São Paulo, v. 17, n. 1, p. 7-20, mar. 2008.

MEADOWS, D. H. Indicators and Information Systems for Sustainable Development. Hartland Four Corners: Sustainability Institute, 1998.

MENEZES, E. C. O.; RONCONI, L. F. A.; SERVA, M. R. Governança dos Recursos de Uso Comum e Desenvolvimento Territorial Sustentável: análise dos Arranjos Institucionais da Pesca na Grande Florianópolis. Revista de Gestão Social e Ambiental, v. 10, n. 1, p. 22-40, 2016.

MOURA, A. S.; BEZERRA, M. C. Governança e sustentabilidade das políticas públicas no Brasil. In: MOURA, A. M. M. (Org.). Governança Ambiental no Brasil: instituições, atores e políticas públicas. Brasília: IPEA, 2016.

NASCIMENTO, D. C. do et al. Sociedade Civil e Governo na Gestão de Cidades: a incidência do Movimento Nossa $\mathrm{BH}$ nas políticas públicas. Future Studies Research Journal, v. 8, n. 2, p. 28-56, abr/ago, 2016.

PECQUEUR, B. A guinada territorial da economia global. Eisforia, v. 4, p. 81103, 2006.

SACHS, I. Rumo à ecossocioeconomia: teoria e prática do desenvolvimento. Cortez, 2007.

SCHOMMER,P.C.;NUNES,J.T;;MORAES, R.L.Accountability,controle social e coprodução do bem público: a atuação de vinte observatórios sociais brasileiros voltados à cidadania e à educação fiscal. In: SEMINÁRIO DEMOCRACIA, DIREITO E GESTÃO PÚBLICA, 3., 2011, Brasília. Anais... Brasília: AGU, 2011. p. 229-258.

VAN BELLEN, H. M. Indicadores de sustentabilidade: uma análise comparativa. Rio de Janeiro: FGV Editora, 2005.

Recebido: 01/02/2019.

Aceito: 14/05/2019. 


\title{
DEMOCRATIC CHALLENGES OF BUILDING AND IMPLEMENTING INDICATORS: CASE “PROGRAMA CIDADES SUSTENTÁVEIS”
}

\begin{abstract}
The concept of Sustainable Cities, which could be seen as an oxymoron, has been widely used in the field of theory and practices. In Brazil, organized civil society promotes the "Sustainable Cities Program (PCS)", which aims to be an agenda for sustainability and has as one of its fundamentals the indicators for monitoring public management goals. The objective of this article is to understand the process of construction and implementation of these indicators. The methodological procedures involve semi-structured interviews with actors of organized civil society who support municipalities in the development in planning and choosing collection of indicators. As findings, we realize that PCS advances by highlighting the importance of indicators as a management tool at the municipal level and developing databases, however, there are still challenges: data-drivenness, governance of indicators, especially in communicating and translating a clear sustainability.
\end{abstract}

Keywords: Sustainable Cities. Sustainability indicators. Social control. Environmental governance. Sustainable governance.

\section{DESAFÍOS DEMOCRÁTICOS A LA CONSTRUCCIÓN E IMPLEMENTACIÓN DE INDICADORES: EL CASO DEL “PROGRAMA CIDADES SUSTENTÁVEIS”}

\begin{abstract}
Resumen
El concepto de Ciudades Sustentables, que podría ser en principio un oxímoron, ha sido ampliamente utilizado en el campo teórico y las prácticas, incluso por el gobierno. En Brasil, a partir de 2012, la sociedad civil organizada promueve el "Programa Cidades Sustentáveis (PCS)" que tiene por objetivo funcionar como una agenda para la sostenibilidad y tiene como uno de sus fundamentos los indicadores para monitoreo de las metas de gestión pública. Este artículo busca comprender el proceso de construcción e implementación de esos indicadores, a partir de entrevistas semiestructuradas con actores de la sociedad civil organizada que apoyan municipios en el desarrollo del plan de metas y elección/ recolección de indicadores. Se percibe que el PCS avanza al destacar la importancia de indicadores como instrumento de gestión a nivel municipal y desarrollar bases de datos, sin embargo, todavía encuentra desafíos en cuanto a la datadriveness, a la gobernanza de los indicadores, sobre todo en comunicar y traducir una noción clara de sostenibilidad.
\end{abstract}

Palabras clave: Ciudades sostenibles. Indicadores de sostenibilidad. Control social. Gobernanza ambiental. Gobernanza sostenible. 